Article

\title{
Antimicrobial Potential and Cytotoxicity of Silver Nanoparticles Phytosynthesized by Pomegranate Peel Extract
}

\author{
Renan Aparecido Fernandes ${ }^{1,2}$, Andresa Aparecida Berretta ${ }^{3}$, Elina Cassia Torres ${ }^{3}$, \\ Andrei Felipe Moreira Buszinski ${ }^{3}$, Gabriela Lopes Fernandes ${ }^{2}$, Carla Corrêa Mendes-Gouvêa ${ }^{2}$, \\ Francisco Nunes de Souza-Neto ${ }^{4}$, Luiz Fernando Gorup ${ }^{4,5}$, Emerson Rodrigues de Camargo ${ }^{4}$ \\ and Debora Barros Barbosa ${ }^{2, *}$ \\ 1 Department of Dentistry, University Center of Adamantina (UNIFAI), Adamantina 17800-000, São Paulo, \\ Brazil; renanfernandes@fai.com.br \\ 2 Department of Dental Materials and Prosthodontics, São Paulo State University (UNESP), School of \\ Dentistry, Araçatuba 16015-050, São Paulo, Brazil; fernandesgabriela@hotmail.com (G.L.F.); \\ carla_cmendes@hotmail.com (C.C.M.-G.) \\ 3 Laboratory of Research, Development \& Innovation, Apis Flora Industrial e Comercial Ltda., Ribeirão Preto \\ 14020-670, São Paulo, Brazil; andresa.berretta@apisflora.com.br (A.A.B.); elinacassia@hotmail.com (E.C.T.); \\ andrei.buszinski@apisflora.com.br (A.F.M.B.) \\ 4 Department of Chemistry, Federal University of São Carlos, São Carlos 13565-905, São Paulo, Brazil; \\ francisconsn29@gmail.com (F.N.S.-N.); lfgorup@gmail.com (L.F.G.); camargo@ufscar.br (E.R.C.) \\ 5 FACET-Department of Chemistry, Federal University of Grande Dourados, Dourados 79804-970, \\ Mato Grosso do Sul, Brazil \\ * Correspondence: debora@foa.unesp.br; Tel.: +55-18-3636-3284
}

Received: 27 April 2018; Accepted: 25 June 2018; Published: 26 June 2018

\begin{abstract}
The phytosynthesis of metal nanoparticles is nowadays attracting the increased attention of researchers and is much needed given the worldwide matter related to environmental contamination. The antimicrobial activity of colloidal and spray formulation of silver nanoparticles (AgNPs) synthesized by pomegranate peel extract against Candida albicans and Staphylococcus aureus, and their cytotoxicity in mammalian cells were tested in the present study. Dry matter, $\mathrm{pH}$, total phenolics, and ellagic acid in the extract were determined. Then, AgNPs were phytosynthesized and characterized by X-ray diffraction, electron transmission microscopy, dynamic light scattering, zeta potential, and $\mathrm{Ag}^{+}$dosage. Spray formulations and respective chemical-AgNP controls were prepared and tested. The peel extract reduced more than $99 \%$ of $\mathrm{Ag}^{+}$, and produced nanoparticles with irregular forms and an 89-nm mean size. All AgNP presented antimicrobial activity, and the spray formulation of green-AgNP increased by 255 and 4 times the effectiveness against S. aureus and C. albicans, respectively. The cytotoxicity of colloidal and spray green-AgNP was expressively lower than the respective chemical controls. Pomegranate peel extract produced stable AgNP with antimicrobial action and low cytotoxicity, stimulating its use in the biomedical field.
\end{abstract}

Keywords: silver; nanoparticles; Candida albicans; Staphylococcus aureus; herbal medicine; Punicaceae

\section{Introduction}

Recently, a state of alert on a topic that affects people globally, antimicrobial resistance, has received much attention. This has led to the deaths of more than 700,000 people a year worldwide and this number has risen every year [1]. It is estimated that there will be a reduction in the world population of 11-444 million people in 2050 if antimicrobial resistance is not bypassed [1]. 
As an alternative against antimicrobial resistance, one approach gaining in strength is the use of inorganic particles at the nanoscale. The most prominent metals in the group of inorganic nanoparticles are copper, zinc, titanium, magnesium, gold, and silver [2-4]. In this context, silver nanoparticles have been the most exploited as they have a wide range of toxicity against several microorganisms such as Staphylococcus aureus, Escherichia coli, Candida albicans, and others [5].

The incorporation and use of silver nanoparticles has been observed in sundry sectors, for instance, in the food industry as an attempt to produce packaging with antimicrobial activity [6]. Its use in the area of cosmetics has also received prominence, as has its use in housecleaning, antiseptics, sunscreens, soap, and shampoo [7-9] as well as in textile manufacturing [10].

Considering the synthesis of silver nanoparticles, many routes have been presented such as electrochemical [11], radiation [12], photochemistry [13], and by biological methods [14]. Phytochemical synthesis has been noteworthy since the use of chemical compounds may result in undesirable toxic effects not only for the human organism but also for the environment. Its effectiveness in the production of silver nanoparticles has been demonstrated by the use of compounds of different plants in the ion reduction, being characterized as rapid, low cost, and environmentally friendly synthesis [15]. Furthermore, green-silver nanoparticles are usually less cytotoxic when compared to those reduced by conventional chemical agents [16]. It is believed that silver nanoparticles reduced by plant extracts do not carry on their surface chemical compounds used for the reduction and stabilization of chemically produced silver nanoparticles that are toxic to human cells. It is still believed that the phytochemicals present in the extracts are carried on the surface of the silver nanoparticles, reducing their cytotoxic effect, aside from presenting different forms of chemically produced silver nanoparticles [16]. Important aspects in green-synthesis should be taken into account including the choice of plant to be used, being the plants which grow in different regions of the world more eligible for this [16]. The previously known potential of the plant including antioxidant, anti-inflammatory, and antimicrobial such as the case of Punica granatum (pomegranate) should also be considered [17-19]. Some studies have also used Punica granatum to reduce silver ions to silver nanoparticles [19-21]. Silver nanoparticles were green-synthesized and showed significantly lower cytotoxicity when compared to the silver nanoparticles synthesized by a chemical pathway. This fact has stimulated the search for the use of reduced silver nanoparticles by means of plant extracts for biological purposes such as the treatment of contagious infectious diseases, especially those in need of topical treatment.

Thus, taking together the benefits of pomegranate and the antimicrobial applicability of silver nanoparticles, the present study aimed to synthesize silver nanoparticles using pomegranate peel extract, and to produce spray formulations containing the previously green-synthesized silver nanoparticles. Their antimicrobial activity against Staphylococcus aureus and Candida albicans, and their cytotoxicity effect on fibroblast cells were investigated.

\section{Results}

\subsection{Characterization of Peel Extract, Silver Nanoparticles and Formulations}

The $\mathrm{pH}$ and the dry matter of the peel extract obtained by maceration followed by percolation were 3.13 and $86.39( \pm 0.96) \% w / w$, and the total phenolics expressed in gallic acid and the ellagic acid were $392.0( \pm 9)$ and $3.64( \pm 0.03) \mathrm{mg} / \mathrm{g}$, respectively.

The formation of silver nanoparticles was confirmed by comparing the XRD patterns and the corresponding standard patterns of cubic of silver nanoparticles (Figure 1), according to the diffraction standard (JCPDS file No. 04-0783). The reflection peak (2 22 2) is characteristic of the substrate (Si), where silver particles were deposited as a thin film. TEM images (Figure 2) showed different forms and sizes of silver nanoparticles produced by green and conventional chemical routes as well as in their respective formulations. In general, green-synthesis produced particles with a larger size than those obtained by conventional synthesis. Dynamic Laser Scanning (DLS) analyses of the formulations prepared with green or conventional silver nanoparticles demonstrated different particle sizes, being 
the mean values of $89 \pm 21$ and $19 \pm 4 \mathrm{~nm}$ for the green and conventional formulation, respectively. The values of zeta potential of green and conventional silver nanoparticles were lower than $-30 \mathrm{mV}$ $(-46.2 \pm 6.06 \mathrm{mV}$ green, and $-67.5 \pm 3.69 \mathrm{mV}$ conventional), indicating the stability of both colloidal silver nanoparticles.

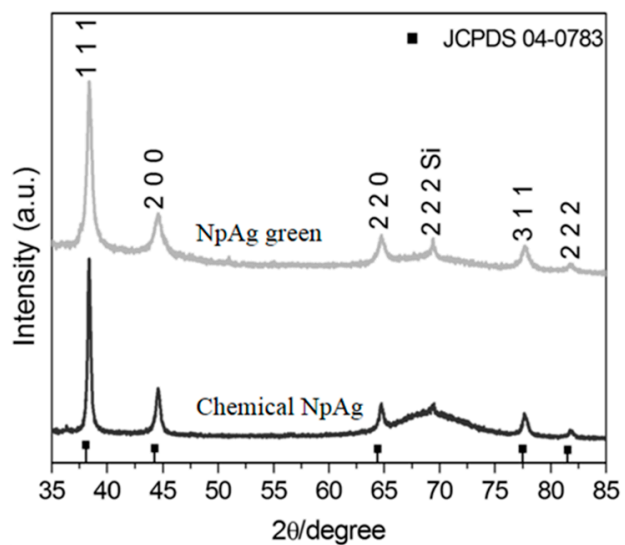

Figure 1. X-ray diffraction (XRD) of the green and chemical silver nanoparticles.

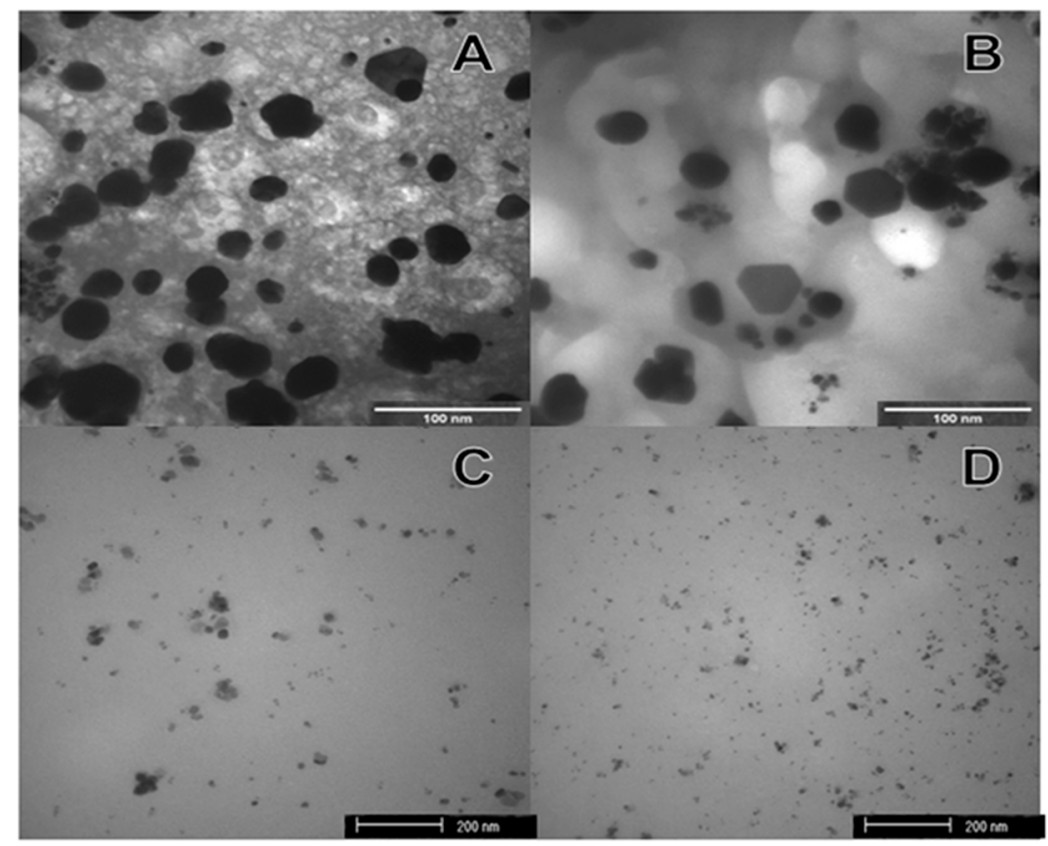

Figure 2. Images of transmission electron microscopy (TEM): (A) Green silver nanoparticles; (B) Silver nanoparticles green formulation; (C) Chemical silver nanoparticles; (D) Silver nanoparticles chemical formulation.

Almost $100 \%$ of the $\mathrm{Ag}^{+}$ions coming from $\mathrm{AgNO}_{3}$ were reduced by the pomegranate peel extract $(99.89 \%)$ and sodium citrate $(99.51 \%)$. However, in the spray formulation containing chemical-silver nanoparticles, the percentage of reduction was diminished to $68.18 \%$ although the formulation maintained stable regarding $\mathrm{Ag}^{+}$ions concentration for 28 days (Table 1). Zeta potential data confirmed the stability of the spray formulations regardless of the method used to obtain the silver nanoparticles (Table 2). The total phenolics in the spray formulations with or without silver nanoparticles were quantified at $0,7,14$, and 28 days after having been prepared (Figure 3), and it has been significantly reduced in the green-synthesized silver nanoparticle formulation after 14 days with values ranging from 0.405 to $0.295 \mathrm{mg} / \mathrm{g}$. 
Table 1. Values of the silver ionic reduction and zeta potential for green and chemical silver nanoparticle formulations in different periods.

\begin{tabular}{ccccccc}
\hline \multirow{2}{*}{ Time } & \multicolumn{2}{c}{ Silver Nanoparticles Green Formulation } & \multicolumn{2}{c}{ Silver Nanoparticles Chemical Formulation } \\
\cline { 2 - 6 } & $\boldsymbol{\mu} \mathbf{g A g} / \mathbf{m L}$ & \% of Reduction & Zeta Potential & $\boldsymbol{\mu g} \mathbf{A g}^{+} / \mathbf{m L}$ & \% of Reduction & Zeta Potential \\
\hline T0 & 0.249 & $99.93 \%$ & $-73.7 \pm 6.49$ & 1.769 & $68.15 \%$ & $-78.2 \pm 3.06$ \\
T7 & 0.178 & $99.95 \%$ & $-68.3 \pm 4.92$ & 1.927 & $65.31 \%$ & $-72.9 \pm 3.10$ \\
T14 & 0.220 & $99.94 \%$ & $-72.8 \pm 6.49$ & 1.543 & $72.22 \%$ & $-85.5 \pm 3.36$ \\
T28 & 0.186 & $99.95 \%$ & $-68.6 \pm 5.62$ & 1.846 & $66.77 \%$ & $-76.5 \pm 4.05$ \\
\hline
\end{tabular}

Table 2. Silver ion concentration $\left(\mu \mathrm{gAg}{ }^{+} / \mathrm{mL}\right)$ and percentage of silver ions reduction after the reactions, AgNP percentage, and values of minimum inhibitory concentration (MIC) of silver nanoparticles and pomegranate peel extract found for Staphylococcus aureus and Candida albicans.

\begin{tabular}{|c|c|c|c|c|c|}
\hline \multirow{2}{*}{ Samples } & \multirow{2}{*}{$\begin{array}{c}\text { Silver Ions } \\
\text { Concentration }\end{array}$} & \multirow{2}{*}{$\begin{array}{c}\text { Silver Ions } \\
\text { Remaining \% }\end{array}$} & \multirow{2}{*}{ Ag NP \% } & \multicolumn{2}{|c|}{$\operatorname{MIC}(\mu \mathrm{g} / \mathrm{mL})$} \\
\hline & & & & S. aureus & C. albicans \\
\hline Control* & $10,303.26$ & 95.52 & 4.48 & 4.13 & 4.59 \\
\hline Pomegranate peel extract & - & - & - & 391 & 781 \\
\hline Silver nanoparticles green & 10.89 & 0.11 & 99.89 & 67.50 & 68.75 \\
\hline Silver nanoparticles chemical & 130.40 & 1.21 & 98.79 & 0.50 & 0.25 \\
\hline Pomegranate peel extract formulation & - & - & - & 0.37 & 0.18 \\
\hline Silver nanoparticles green formulation & 0.249 & 0.01 & 99.99 & 0.26 & 16.87 \\
\hline Silver nanoparticles chemical formulation & 1.769 & 31.85 & 68.15 & 0.56 & 1.12 \\
\hline
\end{tabular}

${ }^{*}$ Control = Carboxymethylcellulose, propylene glycol, silver nitrate.

Silver nanoparticles green formulation

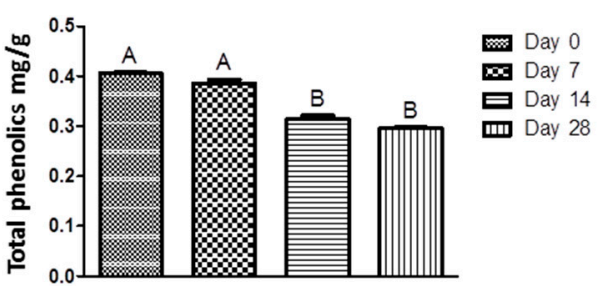

Pomegranate peel extract formulation

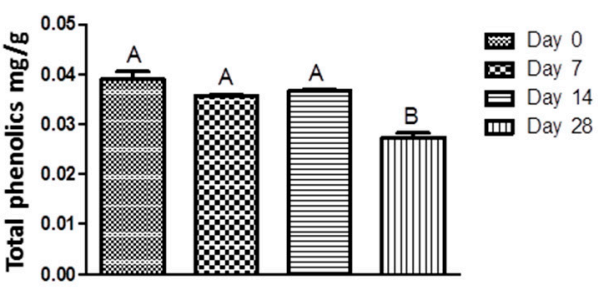

Different capital letters denote significant differences $(\mathrm{p}<0.05$; one-way ANOVA followed by Tukey's Multiple Comparison Test) among the groups.

Figure 3. Total phenolics concentration for the silver nanoparticles green formulation and pomegranate peel extract formulation in different periods. Different capital letters denote significant difference $(p<0.05$; one-way ANOVA followed by Tukey's multiple comparison test) among the groups.

\subsection{Antimicrobial Activity}

The antimicrobial activity expressed as MIC values of silver nanoparticles and pomegranate peel extract $(\mu \mathrm{g} / \mathrm{mL})$ (Table 1) was, in general, considerably lower for the spray formulations than the active inputs regardless of the microorganisms tested. MIC values against $C$. albicans for active inputs and spray formulations were 781 and 0.18 for the peel extract, 68.75 and 16.87 for the green-, and 0.25 and 1.12 for the chemical-silver nanoparticles. While for S. aureus, the values were 391 and $0.37,67.5$, and 0.26 , and 0.5 and 0.56 for pomegranate peel extract, green-, and chemical-silver nanoparticles in the active inputs and spray formulations, respectively. In addition, different conditions of humidity and temperature did not affect the effectiveness of the spray formulations against both microorganisms.

\subsection{Cytotoxicity}

Figure 4 shows the fibroblast L929 cells viability in view of different concentrations of silver nanoparticles (green and conventional route). Green silver nanoparticles presented lower cytotoxicity than conventional ones. A dosage of $50 \mu \mathrm{g} / \mathrm{mL}$ was necessary to initiate the toxicity, but the 
cell viability was nearly $80 \%$, while conventional-silver nanoparticles were quite toxic at very low concentration $(6.25 \mu \mathrm{g} / \mathrm{mL})$ and was similar to the negative control (DMSO) with viability lower than $20 \%$. Furthermore, the addition of the reagents to prepare the formulations did not interfere in the toxicity of the conventional-silver nanoparticles, whereas the cytotoxicity for the green-silver nanoparticles formulation as well as for the extract formulation was considerably increased.

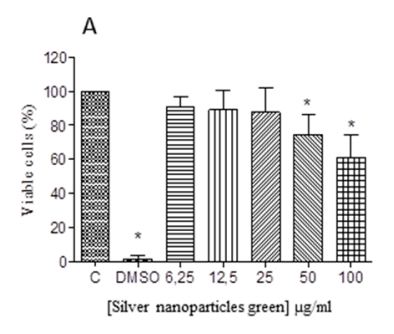

E

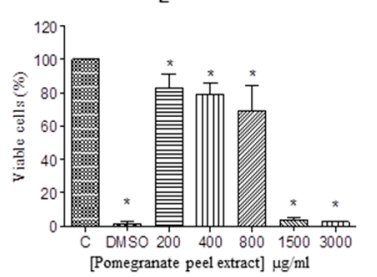

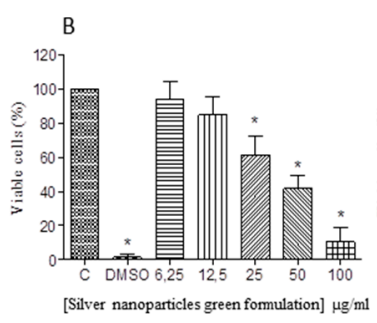

$\mathrm{F}$

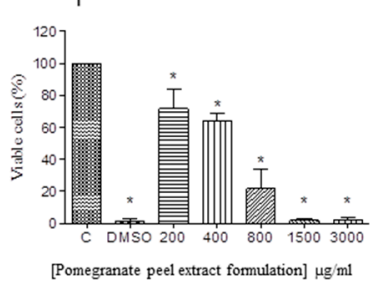

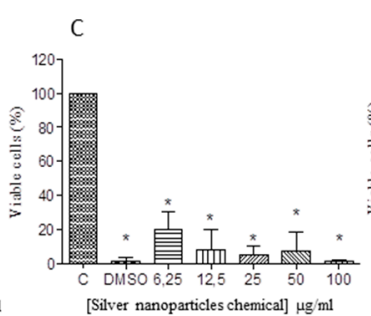

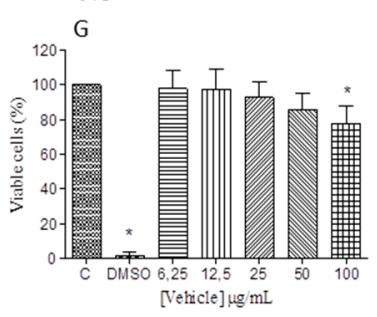

D

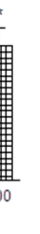

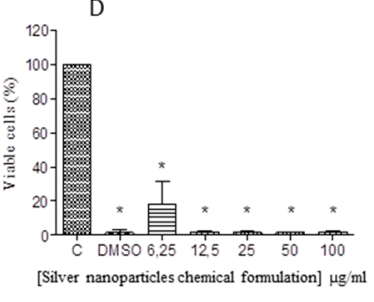

Figure 4. Cytotoxicity evaluation of respective active input (green and chemical silver nanoparticles and pomegranate peel extract), their respective formulations, and the vehicle (compounds of spray-formulation without the active inputs). (A) Silver nanoparticles green; (B) Silver nanoparticles green formulation; (C) Silver nanoparticles chemical; (D) Silver nanoparticles chemical formulation; (E) Pomegranate peel extract; (F) Pomegranate peel extract formulation and (G) Vehicle.

\section{Discussion}

For future reproducibility of the experiment, the extract obtained by maceration followed by percolation was duly characterized in relation to dry matter, total phenolics content, ellagic acid, and $\mathrm{pH}$. Total phenolics were determined only in samples that contained the pomegranate peel extract, and then the chemical formulation did not present any phenolic content in its composition. Polyphenols are effective hydrogen donors and are correlated to the number and position of hydroxyl groups and conjugations as well as the presence of donor electrons in the aromatic ring B, because of the ability of this aromatic ring to withstand the electron depletion located in the $\pi$ electron system [22]. The antimicrobial activity of various polyphenols and plant extracts have been evaluated in pharmaceutical and food studies [23,24]. Some phenolic compounds present in sage, rosemary, thyme, hops, coriander, tea, cloves, and basil are known to exhibit antimicrobial effects against foodborne pathogens. Their mechanisms of action need to be further elucidated, and might be due to a plethora of phenolic compounds present in a very single plant extract. Furthermore, as the bioactive compounds in the extract presented antioxidant and anti-inflammatory activities, the antimicrobial potential of the pomegranate peel extract in the in vivo trials could show better results, and should be strongly stimulated in further studies. Regarding the multi conceptual nature of the term antioxidant and bringing it into the context of this study, some polyphenols present in low concentrations could prevent or reduce the extent of oxidative damage in mammalian cells. Taken together, these natural biomolecules could indirectly protect the cells and reduce the cytotoxicity of silver nanoparticles.

The correct selection of the plant and the standardization of the methods to obtain the extracts to be used as reducing or capping agent in the nanosynthesis of metal particles should be preponderant when the green process is elected for the production of products in large scale. Additionally, a plethora of plants used in the phytosynthesis of metal nanoparticles [25-27] and the lack of information of the 
extraction techniques used in the articles has hindered the comparison of the present results with those found in the literature. For instance, different values and methods of total phenolics quantification can be observed in the literature as described by Kalaycioglu et al. (2017) [28]. Similarly, other factors can interfere in the evaluation and comparisons of the extracts such as the chemical and genotypic composition of the plant, the variety and the soil type, the place of the plant origin, the harvest season, maturation method, aside from the solvent and the process used for the obtention of the pomegranate extract, among others [29].

Scanning electron microscopy (SEM) and transmission electron microscopy (TEM) images showed the smallest particles obtained by conventional chemical synthesis, and DLS data confirmed these findings with mean sizes of 89 and $19 \mathrm{~nm}$ for green and chemical nanoparticles, respectively. The fission of colloidal particles of different sizes and shapes may be related to additives (salts, polymers), solvent properties (boiling temperature, affinity with created surfaces), the addition of nucleation, among others [30]. The reagents used in the chemical synthesis would produce particles with more predictable characteristics than the several substances and compounds present in the plant extract and used in the phytosynthesis route, which would interfere with the size and form of the nanoparticles and make phytosynthesis a challenge in controlling the reaction process and the morphological aspects of the particles. Moreover, the presence of different bioactive substances in the extract would reduce only a fraction of the silver ions present in the solution. The remaining silver ions would form other nuclei and further the growth of the previously formed silver nanoparticles [31]. This process is called Ostwald Ripening, where the largest particles consume the smaller ones and grow larger, where the dissolution of the smaller ones and deposition of ions on the surface of larger ones occur [32].

Almost $100 \%$ of ions reduction was observed for both synthesis routes. However, when the chemical silver nanoparticles were added to the formulation, a dissociation of ions from nearly $30 \%$ was observed when compared to chemical silver nanoparticles alone. This fact could be due to the presence of the components as carboxymethylcellulose and propylene glycol in the spray formulation which possibly favored the silver ion dissociation into the system [33]. The presence of oxygen or ligands for $\mathrm{Ag}^{+}$in the formulations may increase the dissolution rate of AgNP and lead to increased dissolution through the formation of $\mathrm{Ag}^{+}$complexes [34]. $\mathrm{Ag}^{+}$in solution will interact with various ions and molecules that are present in aqueous media. Important ligands to be considered for $\mathrm{Ag}^{+}$are sulfide and organic ligands such as the carboxylic acids group which are used as Ag coatings (e.g., citrate, lactate). Carboxyl ligands such as carboxymethylcellulose strongly bind $\mathrm{Ag}^{+}$, which may affect the dissolution of AgNP and the bioavailability of $\mathrm{Ag}^{+}$[35].

Furthermore, the size of the Ag in the NP affects the extent and kinetics of the AgNP dissolution as the smallest nanoparticles dissolve faster and to a greater extent [36]. This would explain the difference in the dissolution of the nanoparticles in the formulations. Their dissolution is of high relevance for the possible toxic effects of AgNP as $\mathrm{Ag}^{+}$appears in many cases to determine their toxicity [37]. This fact was not observed when green-synthesis was carried out. This could be related to several compounds present in the extract which would readily react with the released silver ions, or the encapsulation of the silver nanoparticles promoted by those phytocompounds may have avoided the silver ions dissociation from the silver nanoparticles and its release to the solution.

Zeta potential test demonstrated the stability of the silver nanoparticles, most notedly in the spray formulations. Electrical charges on the surface of the nanoparticles prevent agglomeration, and thus afford the stability of the nanoparticles [38,39]. Indeed, silver nanoparticles and spray formulations presented a mean of $70 \mathrm{mV}$, which indicates their high stability of silver nanoparticles [40].

Antimicrobial results are also promising for the silver nanoparticles as well as the pomegranate extract obtained. The formulations notably showed better results when compared with the input active only. This fact could be explained for the proper dispersion of the active inputs (silver nanoparticles and pomegranate peel extract) in the spray formulation. Additionally, a synergistic effect could have occurred between those active inputs and the methylparaben present in the formulation. In the literature, studies with an antimicrobial effect of pomegranate extract were conducted against 
Staphylococcus aureus, Enterobacter aerogene, Salmonella typhi, and Klebsiella pneumonia [41]. The MIC values obtained in this study for pomegranate extract were in accordance with Bakkiyaraj et al. (2013) [42] for both the microorganisms studied, and a difference was observed in C. albicans, but this fact may be explained by the difference between the C. albicans strains used in the studies.

Chemical-silver nanoparticles, in formulation or not, produced MIC values against S. aureus about 10-fold lower than those produced by Prema et al. (2017) [33] (60 $\mu \mathrm{g} / \mathrm{mL}$ ), who also produced silver nanoparticles stabilized with CMC. Indeed, the antimicrobial activity of chemical silver nanoparticles was also determined by Monteiro et al. (2011) [43] with MIC values for C. albicans $(0.5 \mu \mathrm{g} / \mathrm{mL}) \mathrm{in}$ accordance with this present study.

Noteworthy is the difference found in the present study in respect of cytotoxicity between the chemical and green routes to obtain silver nanoparticles. Studies have shown that silver nanoparticles produced with Protium serratum and Nyctanthes arbortristis extracts were biocompatible when tested in L929 fibroblasts [44,45]. It is believed that what makes the silver nanoparticle toxic to human cells is the type of reducing agent used such as sodium citrate or sodium borohydride [46]. Even in conventional syntheses of silver nanoparticles, reagents are used that prevent the aggregation of these nanoparticles [47], which may further favor their cytotoxicity.

In the case of phytosynthesis of metal nanoparticles, plant extracts, aside from acting as reducing agents, would act to stabilize the particles against dissolution, hence reducing the toxicity of the silver nanoparticles solution. Furthermore, it is possible that some compounds in the extracts may have a synergistic effect with the silver nanoparticles [48], making them less toxic to human cells. Furthermore, extracts of Punica granatum have exhibited antioxidant [49] and anti-inflammatory [50] activity, and may have contributed to reducing the cytotoxicity of green- in comparison with chemical-silver nanoparticles.

In general, the stability assay (silver ions dosage, zeta potential, and antimicrobial activity) showed a high stabilizing capacity of the formulations. However, the spray formulations of green silver nanoparticles and pomegranate peel extract showed a significant reduction in the content of total phenolics in 14 and 28 days. The decrease in the content of total phenolics may have occurred due to the temperature variations inherent in the stability test, as occurred in the study of [51] where the temperature affected the total phenolics content in the roselle-mango juice blends. Moreover, in formulations containing green-silver nanoparticles, the components of the extract may have been degraded or associated with the nanoparticles, explaining the faster decrease of the total phenolics content when compared to the pomegranate extract formulation. Interestingly, ion dosage, zeta potential, and antimicrobial activity were not affected by different conditions of temperature, time, and humidity of the stability test.

Altogether, the reported results suggest that the plant extract mediated syntheses of AgNP showed a pronounced lower cytotoxic effect in mouse fibroblast cells (L929) than the syntheses of AgNP by the chemical method. Of note is the implication that different sizes between the green-chemical-AgNP as well as the expected impurities sedimented on both obtained nanoparticles could have had on their toxicity. Although it is quite tricky to obtain AgNP with a well-defined form and size and prevent the particles aggregation [52], it is of importance to complement and support our findings, then strongly recommend an eco-friendly approach to producing green-AgNP and prototype wound-care sprays containing these particles.

\section{Materials and Methods}

\subsection{Plant Material and Preparation of Pomegranate Peel Extract}

Pomegranate samples were collected from a crop cultivated in Eixo $\left(21^{\circ} 08^{\prime} 01^{\prime \prime} \mathrm{S}, 51^{\circ} 06^{\prime} 06^{\prime \prime} \mathrm{W}\right)$, Mirandópolis, São Paulo, Brazil, during May 2015. Pomegranate peels were separated and stove-dried at $50{ }^{\circ} \mathrm{C}$, ground, and sieved to a granulometry lower than $2 \mathrm{~mm}$. Peels were submitted to alcohol extraction using $70 \%$ ethanol by maceration, followed by the percolation process [53]. The extract was 
characterized in relation to $\mathrm{pH}$, dry matter, and total phenolics expressed as gallic acid. The chemical marker of pomegranate, ellagic acid, was also identified and quantified.

\subsubsection{Determination of Total Phenolics, $\mathrm{pH}$, and Dry Matter}

To determine the total phenolics, an analytical curve of gallic acid (Sigma-Aldrich Chemical Co., St. Louis, MO, USA) was carried out [54]. All extracts obtained and the standard solution of gallic acid were prepared in $50 \mathrm{~mL}$ volumetric flasks using water as the solvent. The samples were homogenized and, the flasks were brought to the ultrasonic bath for $30 \mathrm{~min}$. A $0.5 \mathrm{~mL}$ aliquot was transferred to another $50 \mathrm{~mL}$ flask where $2.5 \mathrm{~mL}$ of Folin-Denis reagent (Qhemis-High Purity, Hexis, São Paulo, Brazil) and $5.0 \mathrm{~mL}$ of $29 \%$ sodium carbonate (Cinética, São Paulo, Brazil) were added. The samples were protected from light and the readings were performed after $30 \mathrm{~min}$ in a UV-Vis spectrophotometer at $760 \mathrm{~nm}$ [53]. The $\mathrm{pH}$ was measured direct from a solution of $1 \%$ extract, using a $\mathrm{pH}$ kit (Merck $\mathrm{KGaA}$, Darmstadt, Germany) and dry matter was calculated after drying on a sample stove at $105^{\circ} \mathrm{C}$ and was expressed in percentage $w / w$. All data were analyzed in triplicate.

\subsubsection{Determination of the Ellagic Acid Content}

A Shimadzu liquid chromatograph and a Shimpack ODS C18 (Shimadzu Corporation, Kyoto, Japan) reverse phase column $(100 \mathrm{~mm} \times 2.6 \mathrm{~mm})$ were used to determine the ellagic acid content by high performance liquid chromatography (HPLC). Analytical conditions were optimized based on de Sousa et al. (2007) [55] with modifications. As the mobile phase, HPLC grade methanol and a $2 \%$ aqueous acetic acid solution with gradient elution $(0-7 \mathrm{~min}, 20-72.5 \% \mathrm{v} / \mathrm{v}$ methanol, $7-7.5 \mathrm{~min}$, $72.5-95 \% \mathrm{v} / \mathrm{v}$ methanol, $7.5-8.5 \mathrm{~min} 95 \% \mathrm{v} / \mathrm{v}$ methanol, 8.5-9 $\min 95-20 \% \mathrm{v} / \mathrm{v}$ methanol, $9-10 \mathrm{~min}$ $20 \% \mathrm{v} / \mathrm{v}$ methanol) were used. The flow rate was $1.0 \mathrm{~mL} / \mathrm{min}$, and the separation was achieved at $25^{\circ} \mathrm{C}$. The injection volume was $5 \mu \mathrm{L}$ and the wavelength used was $254 \mathrm{~nm}$. Peaks were determined by comparison with an authenticated ellagic acid standard. Briefly, the sample was transferred to a $20 \mathrm{~mL}$ volumetric flask which was diluted with HPLC grade methanol. Extraction was undertaken using a vortex for $5 \mathrm{~min}$ and ultrasonic bath for $1 \mathrm{~h}$. For the extracts, samples were transferred to volumetric flasks of $10 \mathrm{~mL}$, using methanol HPLC as the solvent. All samples were vortexed for $5 \mathrm{~min}$ and sonicated for $30 \mathrm{~min}$. Samples were filtered through $0.45 \mu \mathrm{m}$ filter. All samples were prepared in triplicate.

\subsection{Synthesis of Green-Silver Nanoparticles}

The protocols described by Gorup et al. (2011) [56] and Das et al. 2015 [57] with modifications were used to produce silver nanoparticles. Briefly, 3.5\% of carboxymethylcellulose (CMC) (Labsynth, Diadema, Brazil), 20\% of propylene glycol (PG) (Labsynth, Diadema, Brazil), $100 \mathrm{mM}$ of silver nitrate (SN) (Merck KGaA, Darmstadt, Germany), pomegranate peel extract at $30 \mathrm{mg} / \mathrm{mL}$, and water to make up $100 \%$ of the samples were used. Silver nanoparticles were not purified relative to the excess reagents. The reaction was carried out at $50{ }^{\circ} \mathrm{C}$ for $12 \mathrm{~min}$, and it was selected based on previous results.

\subsection{Synthesis of Chemical-Silver Nanoparticles}

Chemical-silver nanoparticles were produced according to Gorup et al. [53]. $\mathrm{AgNO}_{3}$ (Merck $\mathrm{KGaA}$, Darmstadt, Hesse, Germany) was dissolved in water, and brought to boiling at $90{ }^{\circ} \mathrm{C}$. After 2 min of boiling, an aqueous solution of sodium citrate $\left(\mathrm{Na}_{3} \mathrm{C}_{6} \mathrm{H}_{5} \mathrm{O}_{7}\right)$ (Merck KGaA, Darmstadt, Hesse, Germany) was added, and kept boiling for another 6 min until the solution reached a yellow amber color. The stoichiometric ratio was 1:3, respectively for $\mathrm{AgNO}_{3}$ and $\mathrm{Na}_{3} \mathrm{C}_{6} \mathrm{H}_{5} \mathrm{O}_{7}$. Silver nanoparticles were not purified relative to the excess reagents. 


\subsection{Preparation of the Spray Formulations}

The reagents used were CMC (Labsynth, Diadema, Brazil), PG (Labsynth, Diadema, Brazil), and methylparaben (Labsynth, Diadema, Brazil) in a proportion of $0.1 \%, 7 \%$, and $0.1 \%$, respectively. The active inputs (green- or chemical-silver nanoparticles and pomegranate peel extract) concentrations were based on the minimum inhibitory concentration and cytotoxicity. Therefore, the final concentrations of active inputs in the spray formulations were: $337.5 \mu \mathrm{g} / \mathrm{mL}$ of green-silver nanoparticles, $5.55 \mu \mathrm{g} / \mathrm{mL}$ chemical-silver nanoparticles, and $94 \mu \mathrm{g} / \mathrm{mL}$ of crude peel extract dry matter.

\subsection{Characterization of the Silver Nanoparticles and the Spray Formulations}

\subsubsection{X-ray Diffraction (XRD), Dynamic Light Scattering (DLS), and Zeta Potential Analysis}

A Shimadzu XRD diffractometer with a $\mathrm{Cu} \mathrm{K} \alpha$ radiation operating at $30 \mathrm{kV}$ and $30 \mathrm{~mA}$ and $2 \theta$ range from $35^{\circ}$ to $85^{\circ}$ with step scan of $0.02^{\circ}$ and scan speed $0.2^{\circ} \cdot \mathrm{min}^{-1}$ was used to perform XRD analysis. To collect silver nanoparticles patterns, the nanoparticles were deposited on the surface of a silicon substrate $(\mathrm{Si})$ by dripping the aqueous colloidal dispersion on the substrate at room temperature until the solvent had evaporated.

DLS experiments were performed at room temperature and at a fixed angle of $173^{\circ}$ on a Zetasizer Nano ZS (Malvern Instruments Ltd., Malvern, UK) equipped with $50 \mathrm{~mW} 533 \mathrm{~nm}$ laser and a digital auto correlator. The number-average values obtained were compared to the size distributions of the silver nanoparticles. For the zeta potential test a Zetasizer (Malvern instruments, Malvern, UK) with an MPT-2 titrator was used. Aliquots from each test suspension were obtained to conduct zeta potential, and mean values were obtained from three independent measurements.

\subsubsection{TEM Analyzes}

The nanocompounds morphology was characterized by TEM images in a Jeol JEM-100 CXII (JEOL USA Inc., Peabody, St. Louis, MO, USA) microscope equipped with Hamamatsu ORCA-HR digital camera.

\subsection{Silver Ions Dosage}

The dosages of free silver ions $\left(\mathrm{Ag}^{+}\right)$present in the compounds and spray formulations were performed to observe if the total amount of $\mathrm{Ag}$ added in the synthesis reaction was successfully reduced. A specific electrode 9616 BNWP (Thermo Scientific, Beverly, MA, USA) coupled to an ion analyzer (Orion $720 \mathrm{~A}^{+}$, Thermo Scientific, Beverly, MA, USA) was used. A $1000 \mu \mathrm{g} \mathrm{Ag} / \mathrm{mL}$ standard was prepared by adding $1.57 \mathrm{~g}$ of AgNO3 to $1 \mathrm{~L}$ of deionized water. The combined electrode was calibrated with standards containing 6.25 to $100 \mu \mathrm{g} \mathrm{Ag} / \mathrm{mL}$ to achieve equivalent silver concentrations in the compounds. A silver ionic strength adjuster solution (ISA, Cat. No. 940011) that provided a constant background ionic strength was used ( $1 \mathrm{~mL}$ of each sample/standard: $0.02 \mathrm{~mL}$ ISA).

\subsection{Stability Test of the Spray Formulations}

The spray formulations were submitted to a stability test with controlled conditions of temperature and time. This test was based on Anvisa protocols (Cosmetics stability guide ISBN 85-88233-15-0; Copyright $^{\odot}$ Anvisa, 2005) and the guide to stability studies (Ordinance No. 593 of 25 August 2000). Briefly, samples of each spray formulation were submitted to alternating cycles of temperature daily ranging from 40 to $-5^{\circ} \mathrm{C}$ for 28 days. The tests selected to evaluate the stability of the samples were ion dosage, total phenolics content, zeta potential, and minimal inhibitory concentration (MIC). All tests were done in the same conditions as described before, and were carried out at 0, 7, 14, and 28 days. 


\subsection{Antimicrobial Activity of the Silver Nanoparticles and the Spray Formulations}

Minimal inhibitory concentration of the silver nanoparticles samples were determined following the instructions of the Clinical Laboratory Standards Institute with some modifications. The samples were first diluted in water and subsequently in culture medium specific for each microorganism, Mueller Hinton broth (BD Difco, Franklin Lakes, USA) for Staphylococcus aureus (ATCC 25923), and RPMI (Sigma-Aldrich, St. Louis, MO, USA) for Candida albicans SC 5314) [58]. The microorganisms were adjusted to $5 \times 10^{5}$ cells $/ \mathrm{mL}$ for $S$. aureus and $5 \times 10^{3}$ cells $/ \mathrm{mL}$ for C. albicans, and the plates were incubated for $24 \mathrm{~h}$ and $48 \mathrm{~h}$ in aerobiosis at $37^{\circ} \mathrm{C}$ for S. aureus and C. albicans, respectively. After incubation, the plates were visually read. The assays were performed in triplicate.

\subsection{Cytotoxicity Analysis}

For the evaluation of cytotoxicity, fibroblast cells of the L929 lineage were used. Cells were cultured in DMEM culture supplemented with $10 \%$ fetal bovine serum (FBS), penicillin G $(100 \mathrm{U} / \mathrm{mL})$ (Gibco ${ }^{\circledR}$, Carlsbad, USA), streptomycin $(100 \mu \mathrm{g} / \mathrm{mL})$, amphotericin B $(25 \mu \mathrm{g} / \mathrm{mL})$ and incubated in a stove at $37{ }^{\circ} \mathrm{C}$ with $5 \% \mathrm{CO}_{2}$. Cells were subcultured (5-7 days), using $0.9 \%$ saline to wash them and $0.25 \%$ trypsin to disintegrate them from the vial. After disruption, these cells were centrifuged at $1000 \mathrm{rpm}$ for $10 \mathrm{~min}$ at $10^{\circ} \mathrm{C}$, resuspended in complete DMEM medium (supplemented with FBS), and cell counted in a Neubauer's chamber.

The sub-cultured third to eighth passage fibroblasts were inoculated into 96-well microplates at a density of $0.5 \times 10^{5}$ cells/well. They were then incubated at $37{ }^{\circ} \mathrm{C}$ with $5 \% \mathrm{CO}_{2}$. After $24 \mathrm{~h}$, $20 \mu \mathrm{L}$ of different dilutions of each sample were added to the wells of the plate containing the cells in medium not supplemented with SBF (incomplete medium) and incubated. Twenty-four hours post-treatment, the medium was withdrawn, cells were washed with saline and $20 \mu \mathrm{L}$ of resazurin (Sigma-Aldrich) $0.01 \% w / v$ in deionized $\mathrm{H}_{2} \mathrm{O}$ was added to each well containing $180 \mu \mathrm{L}$ of DMEM medium supplemented with $10 \%$ Of SFB. The plates were then incubated for $4 \mathrm{~h}$ at $37^{\circ} \mathrm{C}$ and fluorescence was measured at 540 and $590 \mathrm{~nm}$ for excitation and emission, respectively [59]. Cell viability was expressed as a percentage of viable cells when compared to the control group without treatment.

\subsection{Statistical Analysis}

GraphPad Prism software (GraphPad Software, Inc., La Jolla, CA, USA) was employed for the statistical analysis with a confidence level of $95 \%$. Parametric statistical analyses were conducted with one-way ANOVA followed by Tukey's multiple comparison test for total phenols and zeta potential. For the ion test the statistical analyses was Dunn's multiple comparison test.

\section{Conclusions}

In light of the results obtained and the limitations of the present study, it was concluded that the use of pomegranate peel extract showed it to be an efficient reducing agent for the production of silver nanoparticles. Moreover, the antimicrobial potential and the low cytotoxicity demonstrated by green-silver nanoparticles have stimulated the search for improvements in the bio-nanotechnology field. Furthermore, the anti-inflammatory and antioxidant properties of pomegranate have encouraged further studies to use nanosystems with future application in prophylaxis or treatment of biofilm-dependent diseases.

Author Contributions: R.A.F., D.B.B., and A.A.B. conceived and designed the experiments; R.A.F., E.C.T., A.F.M.B., G.L.F., and C.C.M.-G. performed the experiments; R.A.F., D.B.B., and A.A.B. analyzed the data; F.N. d.S.-N., L.F.G., and E.R.d.C. contributed reagents/materials/analysis tools; R.A.F. and D.B.B. wrote the paper.

Funding: This study was supported by São Paulo Research Foundation (FAPESP), Brazil, (Process n 2016/04230-9).

Acknowledgments: The authors would like to thank the company Apis Flora Indl. Coml. Ltda. for the facilities and for the production of the spray formulations containing pomegranate peel extract, and the Laboratory of photochemioprotection of the Faculty of Pharmaceutical Sciences of Ribeirão Preto for the facilities in performing some of the laboratory assays. We thank the Brazilian Agricultural Research Corporation (EMBRAPA) to allow 
for some tests on the research on its premises and also the Federal University of São Carlos for disposal of its dependencies and technologies. This research work was supported by the São Paulo Research Foundation (FAPESP), Brazil, (Process nº 2016/04230-9).

Conflicts of Interest: The authors declare no conflict of interest. The founding sponsors had no role in the design of the study; in the collection, analyses, or interpretation of data; in the writing of the manuscript, and in the decision to publish the results.

\section{References}

1. Raut, S.; Adhikari, B. The need to focus China's national plan to combat antimicrobial resistance. Lancet Infect. Dis. 2017, 17, 137-138. [CrossRef]

2. Guzman, M.; Dille, J.; Godet, S. Synthesis and antibacterial activity of silver nanoparticles against gram-positive and gram-negative bacteria. Nanomed. Nanotechnol. Biol. Med. 2012, 8, 37-45. [CrossRef] [PubMed]

3. He, G.; Qiao, M.; Li, W.; Lu, Y.; Zhao, T.; Zou, R.; Li, B.; Darr, J.A.; Hu, J.; Titirici, M.M.; et al. S, N-Co-Doped Graphene-Nickel Cobalt Sulfide Aerogel: Improved Energy Storage and Electrocatalytic Performance. Adv. Sci. 2017, 4, 1600214. [CrossRef] [PubMed]

4. Jankun, J.; Landeta, P.; Pretorius, E.; Skrzypczak-Jankun, E.; Lipinski, B. Unusual clotting dynamics of plasma supplemented with iron(III). Int. J. Mol. Med. 2014, 33, 367-372. [CrossRef] [PubMed]

5. Hebeish, A.; El-Rafie, M.H.; El-Sheikh, M.A.; Seleem, A.A.; El-Naggar, M.E. Antimicrobial wound dressing and anti-inflammatory efficacy of silver nanoparticles. Int. J. Biol. Macromol. 2014, 65, 509-515. [CrossRef] [PubMed]

6. Kuorwel, K.K.; Cran, M.J.; Sonneveld, K.; Miltz, J.; Bigger, S.W. Antimicrobial activity of biodegradable polysaccharide and protein-based films containing active agents. J. Food Sci. 2011, 76, R90-R102. [CrossRef] [PubMed]

7. Bansod, S.D.; Bawaskar, M.S.; Gade, A.K.; Rai, M.K. Development of shampoo, soap and ointment formulated by green-synthesised silver nanoparticles functionalised with antimicrobial plants oils in veterinary dermatology: Treatment and prevention strategies. IET Nanobiotechnol. 2015, 9, 165-171. [CrossRef] [PubMed]

8. Tulve, N.S.; Stefaniak, A.B.; Vance, M.E.; Rogers, K.; Mwilu, S.; LeBouf, R.F.; Schwegler-Berry, D.; Willis, R.; Thomas, T.A.; Marr, L.C. Characterization of silver nanoparticles in selected consumer products and its relevance for predicting children's potential exposures. Int. J. Hyg. Environ. Health 2015, 218, 345-357. [CrossRef] [PubMed]

9. Benn, T.; Cavanagh, B.; Hristovski, K.; Posner, J.D.; Westerhoff, P. The release of nanosilver from consumer products used in the home. J. Environ. Qual. 2010, 39, 1875-1882. [CrossRef] [PubMed]

10. Velazquez-Velazquez, J.L.; Santos-Flores, A.; Araujo-Melendez, J.; Sánchez-Sánchezc, R.; Velasquilloc, C.; Gonzálezd, C.; Martínez-Castañone, G.; Martinez-Gutierreza, F. Anti-biofilm and cytotoxicity activity of impregnated dressings with silver nanoparticles. Mater. Sci. Eng. C Mater. Biol. Appl. 2015, 49, 604-611. [CrossRef] [PubMed]

11. Treshchalov, A.; Erikson, H.; Puust, L.; Tsarenko, S.; Saar, R.; Vanetsev, A.; Tammeveski, K.; Sildos, I. Stabilizer-free silver nanoparticles as efficient catalysts for electrochemical reduction of oxygen. J. Colloid Interface Sci. 2017, 491, 358-366. [CrossRef] [PubMed]

12. Malkar, V.V.; Mukherjee, T.; Kapoor, S. Synthesis of silver nanoparticles in aqueous aminopolycarboxylic acid solutions via gamma-irradiation and hydrogen reduction. Mater. Sci. Eng. C Mater. Biol. Appl. 2014, 44, 87-91. [CrossRef] [PubMed]

13. Lombardo, P.C.; Poli, A.L.; Castro, L.F.; Perussi, J.R.; Schmitt, C.C. Photochemical Deposition of Silver Nanoparticles on Clays and Exploring Their Antibacterial Activity. ACS Appl. Mater. Interfaces 2016, 8, 21640-21647. [CrossRef] [PubMed]

14. Rafique, M.; Sadaf, I.; Rafique, M.S.; Tahir, M.B. A review on green-synthesis of silver nanoparticles and their applications. Artif. Cells Nanomed. Biotechnol. 2016, 8, 1-20. [CrossRef]

15. Roy, N.; Gaur, A.; Jain, A.; Bhattacharya, S.; Rani, V. Green-synthesis of silver nanoparticles: An approach to overcome toxicity. Environ. Toxicol. Pharmacol. 2013, 36, 807-812. [CrossRef] [PubMed]

16. Das, R.K.; Brar, S.K. Plant mediated green-synthesis: Modified approaches. Nanoscale 2013, 5, 10155-101562. [CrossRef] [PubMed] 
17. Lansky, E.P.; Newman, R.A. Punica granatum (pomegranate) and its potential for prevention and treatment of inflammation and cancer. J. Ethnopharmacol. 2007, 109, 177-206. [CrossRef] [PubMed]

18. Pande, G.; Akoh, C.C. Antioxidant capacity and lipid characterization of six Georgia-grown pomegranate cultivars. J. Agric. Food Chem. 2009, 57, 9427-9436. [CrossRef] [PubMed]

19. Edison, T.J.; Sethuraman, M.G. Biogenic robust synthesis of silver nanoparticles using Punica granatum peel and its application as a green catalyst for the reduction of an anthropogenic pollutant 4-nitrophenol. Spectrochim. Acta Part A Mol. Biomol. Spectrosc. 2013, 104, 262-264. [CrossRef] [PubMed]

20. Ahmad, N.S.; Rai, R. Rapid green-synthesis of silver and gold nanoparticles using peels of Punica granatum. Adv. Mater. Lett. 2012, 3, 376-380. [CrossRef]

21. Naik, S.K.; Chand, P.K. Silver nitrate and aminoethoxyvinylglycine promote in vitro adventitious shoot regeneration of pomegranate (Punica granatum L.). J. Plant Physiol. 2003, 160, 423-430. [CrossRef] [PubMed]

22. Ramirez-Tortoza, C.; Andersen, O.M.; Gardner, P.T.; Morrice, P.C.; Wood, S.G.; Duthie, S.J.; Collins, A.R.; Duthie, G.G. Anthocyanin-rich extract decreases indices of lipid peroxidation and DNA damage in vitamin E depleted rats. Free Radic. Biol. Med. 2001, 46, 1033-1037. [CrossRef]

23. Taguri, T.; Takashi, T.; Kouno, I. Antibacterial spectrum of plant polyphenols and extracts depending upon hydroxyphenyl structure. Biol. Pharm. Bull. 2006, 29, 2226-2235. [CrossRef] [PubMed]

24. Ahn, J.; Grun, I.U.; Mustapha, A. Effects of plant extracts on microbial growth, color change, and lipid oxidation in cooked beef. Food Microbiol. 2007, 24, 7-14. [CrossRef] [PubMed]

25. Elemike, E.E.; Onwudiwe, D.C.; Ekennia, A.C.; Ehiri, R.C.; Nnaji, N.J. Phytosynthesis of silver nanoparticles using aqueous leaf extracts of Lippia citriodora: Antimicrobial, larvicidal and photocatalytic evaluations. Mater. Sci. Eng. C Mater. Biol. Appl. 2017, 75, 980-989. [CrossRef] [PubMed]

26. Ovais, M.; Khalil, A.T.; Raza, A.; Khan, M.A.; Ahmad, I.; Islam, N.U.; Saravanan, M.; Ubaid, M.F.; Ali, M.; Shinwari, Z.K. Green-synthesis of silver nanoparticles via plant extracts: Beginning a new era in cancer theranostics. Nanomedicine 2016, 11, 3157-3177. [CrossRef] [PubMed]

27. Soman, S.; Ray, J.G. Silver nanoparticles synthesized using aqueous leaf extract of Ziziphus oenoplia (L.) Mill: Characterization and assessment of antibacterial activity. J. Photochem. Photobiol. B Biol. 2016, 163, 391-402. [CrossRef] [PubMed]

28. Kalaycioglu, Z.; Erim, F.B. Total phenolic contents, antioxidant activities, and bioactive ingredients of juices from pomegranate cultivars worldwide. Food Chem. 2017, 221, 496-507. [CrossRef] [PubMed]

29. Li, Y.; Yang, F.; Zheng, W.; Hu, M.; Wang, J.; Ma, S.; Deng, Y.; Luo, Y.; Ye, T.; Yin, W. Punica granatum (pomegranate) leaves extract induces apoptosis through mitochondrial intrinsic pathway and inhibits migration and invasion in non-small cell lung cancer in vitro. Biomed. Pharmacother. Biomed. Pharmacother. 2016, 80, 227-235. [CrossRef] [PubMed]

30. Martins, M.A.; Trindade, T. Os nanomateriais e a descoberta de novos mundos na bancada do químico. Quím. Nova 2012, 35, 1434-1446. [CrossRef]

31. Agnihotri, S.; Mukerji, S.; Mukerji, S. Size-controlled silver nanoparticles synthesized over the range 5-100 nm using the same protocol and their antibacterial efficacy. RSC Adv. 2014, 4, 3974-3983. [CrossRef]

32. Houk, L.R.; Challa, S.R.; Grayson, B.; Fanson, P.; Datye, A.K. The definition of "critical radius" for a collection of nanoparticles undergoing Ostwald ripening. Langmuir 2009, 25, 11225-11227. [CrossRef] [PubMed]

33. Prema, P.; Thangapandiyan, S.; Immanuel, G. CMC stabilized nano silver synthesis, characterization and its antibacterial and synergistic effect with broad spectrum antibiotics. Carbohydr. Polym. 2017, 158, 141-148. [CrossRef] [PubMed]

34. Gondikas, A.P.; Morris, A.; Reinsch, B.C.; Marinakos, S.M.; Lowry, G.V.; Hsu-Kim, H. Cysteine-induced modifications of zero-valent silver nanomaterials: Implications for particle surface chemistry, aggregation, dissolution, and silver speciation. Environ. Sci. Technol. 2012, 46, 7037-7045. [CrossRef] [PubMed]

35. Solomon, M.M.; Gerengi, H.; Umoren, S.A. Carboxymethyl Cellulose/Silver Nanoparticles Composite: Synthesis, characterization and Application as a Benign Corrosion Inhibitor for St $37 \mathrm{Steel}$ in $15 \% \mathrm{H}_{2} \mathrm{SO}_{4}$ Medium. ACS Appl. Mater. Interfaces 2017, 9, 6376-6389. [CrossRef] [PubMed]

36. Liu, J.; Sonshine, D.A.; Shervani, S.; Hurt, R.H. Controlled release of biologically active silver from nanosilver surfaces. ACS Nano 2010, 4, 6903-6913. [CrossRef] [PubMed]

37. El Badawy, A.M.; Luxton, T.P.; Silva, R.G.; Scheckel, K.G.; Suidan, M.T.; Tolaymat, T.M. 2010. Impact of environmental conditions ( $\mathrm{pH}$, ionic strength, and electrolyte type) on the surface charge and aggregation of silver nanoparticles suspensions. Environ. Sci. Technol. 2010, 44, 1260-1266. [CrossRef] [PubMed] 
38. Sadowski, Z.; Maliszewska, I.H.; Grochowalska, B.; Polowczyk, I.; Koźlecki, T. Synthesis of silver nanoparticles using microorganisms. Mater. Sci. 2008, 26, 419-424.

39. Salem, H.F.; Eid, K.A.M.; Saraf, M.A. Formulation and evaluation of silver nanoparticles as antibacterial and antifungal agents with a minimal cytotoxic effect. Int. J. Drug Deliv. 2011, 3, 293-304.

40. Leite, E.R.; Ribeiro, C. Crystallization and Growth of Colloidal Nanocrystals; Springer: New York, NY, USA, 2012; ISBN 978-1-4614-1308-0.

41. Malviya, S.; Jha, A.; Hettiarachchy, N. Antioxidant and antibacterial potential of pomegranate peel extracts. J. Food Sci. Technol. 2014, 51, 4132-4137. [CrossRef] [PubMed]

42. Bakkiyaraj, D.; Nandhini, J.R.; Malathy, B.; Pandian, S.K. The anti-biofilm potential of pomegranate (Punica granatum L.) extract against human bacterial and fungal pathogens. Biofouling 2013, 29, 929-937. [CrossRef] [PubMed]

43. Monteiro, D.R.; Gorup, L.F.; Silva, S.; Negri, M.; de Camargo, E.R.; Oliveira, R.; Barbosa, D.B.; Henriques, M. Silver colloidal nanoparticles: Antifungal effect against adhered cells and biofilms of Candida albicans and Candida glabrata. Biofouling 2011, 27, 711-719. [CrossRef] [PubMed]

44. Gogoi, N.; Babu, P.J.; Mahanta, C.; Bora, U. Green-synthesis and characterization of silver nanoparticles using alcoholic flower extract of Nyctanthes arbortristis and in vitro investigation of their antibacterial and cytotoxic activities. Mater. Sci. Eng. C Mater. Biol. Appl. 2015, 46, 463-469. [CrossRef] [PubMed]

45. Mohanta, Y.K.; Panda, S.K.; Bastia, A.K.; Mohanta, T.K. Biosynthesis of Silver Nanoparticles from Protium serratum and Investigation of their Potential Impacts on Food Safety and Control. Front. Microbiol. 2017, 8, 626. [CrossRef] [PubMed]

46. Asharani, P.V.; Lian Wu, Y.; Gong, Z.; Valiyaveettil, S. Toxicity of silver nanoparticles in zebrafish models. Nanotechnology 2008, 19, 255102. [CrossRef] [PubMed]

47. Ren, M.; Jin, Y.; Chen, W.; Huang, W. Rich capping ligand-Ag colloid interactions. J. Phys. Chem. C 2015, 119, 27588-27593. [CrossRef]

48. Gengan, R.M.; Anand, K.; Phulukdaree, A.; Chuturgoon, A. A549 lung cell line activity of biosynthesized silver nanoparticles using Albizia adianthifolia leaf. Colloids Surf. B Biointerfaces 2013, 105, 87-91. [CrossRef] [PubMed]

49. Delgado, N.T.; Rouver, W.D.; Freitas-Lima, L.C.; de Paula, T.D.; Duarte, A.; Silva, J.F.; Lemos, V.S.; Santos, A.M.; Mauad, H.; Santos, R.L.; et al. Pomegranate Extract Enhances Endothelium-Dependent Coronary Relaxation in Isolated Perfused Hearts from Spontaneously Hypertensive Ovariectomized Rats. Front. Pharmacol. 2016, 7, 522. [CrossRef] [PubMed]

50. Houston, D.M.; Bugert, J.; Denyer, S.P.; Heard, C.M. Anti-inflammatory activity of Punica granatum L. (Pomegranate) rind extracts applied topically to ex vivo skin. Eur. J. Pharm. Biopharma. 2017, 112, 30-37. [CrossRef] [PubMed]

51. Mgaya-Kilima, B.; Remberg, S.F.; Chove, B.E.; Wicklund, T. Physiochemical and antioxidant properties of roselle-mango juice blends; effects of packaging material, storage temperature and time. Food Sci. Nutr. 2015, 3, 100-109. [CrossRef] [PubMed]

52. Zhang, X.F.; Liu, Z.G.; Shen, W.; Gurunathan, S. Silver Nanoparticles: Synthesis, Characterization, Properties, Applications, and Therapeutic Approaches. Int. J. Mol. Sci. 2016, 17. [CrossRef] [PubMed]

53. De Oliveira, J.R.; de Castro, V.C.; das Gracas Figueiredo Vilela, P.; Camargo, S.E.; Carvalho, C.A.; Jorge, A.O.; de Oliveira, L.D. Cytotoxicity of Brazilian plant extracts against oral microorganisms of interest to dentistry. BMC Complement. Altern. Med. 2013, 13, 208. [CrossRef] [PubMed]

54. Waterman, P.G.; Mole, S. Analysis of Phenolic Plant Metabolites; Blackwell Scientific: Oxford, UK; Boston, MA, USA, 1994.

55. De Sousa, J.P.; Bueno, P.C.; Gregorio, L.E.; da Silva Filho, A.A.; Furtado, N.A.; de Sousa, M.L.; Bastos, J.K. A reliable quantitative method for the analysis of phenolic compounds in Brazilian propolis by reverse phase high performance liquid chromatography. J. Sep. Sci. 2007, 30, 2656-2665. [CrossRef] [PubMed]

56. Gorup, L.F.; Longo, E.; Leite, E.R.; Camargo, E.R. Moderating effect of ammonia on particle growth and stability of quasi-monodisperse silver nanoparticles synthesized by the Turkevich method. J. Colloid Interface Sci. 2011, 360, 355-358. [CrossRef] [PubMed]

57. Das, A.; Kumar, A.; Patil, N.B.; Viswanathan, C.; Ghosh, D. Preparation and characterization of silver nanoparticle loaded amorphous hydrogel of carboxymethylcellulose for infected wounds. Carbohydr. Polym. 2015, 130, 254-261. [CrossRef] [PubMed] 
58. Gillum, A.M.; Tsay, E.Y.; Kirsch, D.R. Isolation of the Candida albicans gene for orotidine-5'-phosphate decarboxylase by complementation of S. cerevisiae ura3 and E. coli pyrF mutations. Mol. Gen. Genet. MGG 1984, 198, 179-182. [CrossRef] [PubMed]

59. Kuete, V.; Wiench, B.; Alsaid, M.S.; Alyahya, M.A.; Fankam, A.G.; Shahat, A.A.; Efferth, T. Cytotoxicity, mode of action and antibacterial activities of selected Saudi Arabian medicinal plants. BMC Complement. Altern. Med. 2013, 13, 354. [CrossRef] [PubMed]

(C) 2018 by the authors. Licensee MDPI, Basel, Switzerland. This article is an open access article distributed under the terms and conditions of the Creative Commons Attribution (CC BY) license (http://creativecommons.org/licenses/by/4.0/). 